\title{
COMUNICAÇÃO ENTRE A EQUIPE DE SAÚDE E A FAMÍLIA DA CRIANÇA COM ASFIXIA PERINATAL GRAVE ${ }^{1}$
}

\author{
Viviane Marten Milbrath², Hedi Crecencia Heckler de Siqueira³, Maria da Graça Corso da Motta4, Simone \\ Coelho Amestoy ${ }^{5}$
}

\footnotetext{
${ }^{1}$ Artigo extraído da dissertação - Cuidado da família à criança portadora de paralisia cerebral nos três primeiros anos de vida, apresentada ao Programa de Pós-Graduação em Enfermagem da Universidade Federal do Rio Grande (FURG), em 2008.

${ }^{2}$ Doutoranda do Programa de Pós-Graduação da Universidade Federal do Rio Grande do Sul (UFRGS). Professora Assistente da Faculdade de Enfermagem da Universidade Federal de Pelotas (UFPel). Rio Grande do Sul, Brasil. E-mail: vivimarten@ ig.com.br

${ }^{3}$ Doutora em Enfermagem. Docente do Programa de Pós-Graduação em Enfermagem da FURG. Rio Grande do Sul, Brasil. E-mail: hedihs@terra.com.br

${ }^{4}$ Doutora em Filosofia em Enfermagem. Docente Adjunto do Departamento de Enfermagem Materno-Infantil da Escola de Enfermagem da UFRGS. Rio Grande do Sul, Brasil. E-mail: mottinha@enf.ufrgs.br

${ }^{5}$ Doutoranda do Programa de Pós-Graduação da Universidade Federal de Santa Catarina. Bolsista do CNPq. Santa Catarina, Brasil. E-mail: samestoy@terra.com.br
}

RESUMO: Este estudo objetivou discutir o processo de comunicação entre equipe de saúde e família, a partir dos resultados da pesquisa intitulada "Cuidado da família à criança portadora de paralisia cerebral nos três primeiros anos de vida". O estudo, qualitativo e exploratório-descritivo, foi realizado no período de janeiro a março de 2008, na cidade de Rio Grande, Rio Grande do Sul, Brasil, tendo como participantes seis famílias. Foram utilizadas entrevistas semiestruturadas para a coleta das informações, as quais foram analisadas segundo Análise Temática, produzindo três unidades temáticas: Muitos informantes e poucas informações; As informações fornecidas pela equipe de saúde versus a compreensão da família; e O "peso/poder" que as falas dos profissionais da saúde têm na vida das famílias. Os resultados mostraram uma série de ruídos no processo de comunicação entre a equipe de saúde e a família da criança que sofreu asfixia perinatal grave, prejudicando o processo dialógico do cuidado.

DESCRITORES: Crianças com deficiência. Família. Comunicação. Asfixia neonatal. Enfermagem.

\section{COMMUNICATION BETWEEN THE HEALTH TEAM AND THE FAMILY OF A CHILD WITH SEVERE PERINATAL ASPHYXIA}

\begin{abstract}
This study aims to discuss the communication process between the health team and family, based on the results of the study called "Family care to a child with cerebral paralisy in the first three years of age". This qualitative, exploratory-descriptive study was performed in Rio Grande, RS, Brazil, from January to March of 2008 with the participation of six families. Semi-structured interviews were used to collect information which, analyzed according Thematic Analysis, produced three thematic units: Many informants and little information; the information provided by the health team versus the family's understanding; and the "weight/power" which the health professionals' talk has on these families' lives. The results showed a series of noises in the communication process between the health team and the child's family who had severe perinatal asphyxia, harming the care dialogue process.
\end{abstract}

DESCRIPTORS: Disabled children. Family. Communication. Asphyxia neonatorum, Nursing.

\section{COMUNICACIÓN ENTRE EL EQUIPO DE SALUD Y LA FAMILIA DEL NIÑO CON ASFIXIA PERINATAL GRAVE}

RESUMEN: Este estudio tuvo como objetivo discutir el proceso de comunicación entre el equipo de salud y la familia, a partir de los resultados de la investigación titulada "Cuidado de la família al niño portador de parálisis cerebral en los tres primeros años de vida". El estudio es cualitativo, exploratorio y descriptivo, realizado entre enero y marzo de 2008, en la ciudad de Rio Grande, Rio Grande do Sul, Brasil, con la participación de seis familias. Para la recolección de los datos se hicieron entrevistas semiestructuradas que, al ser analizadas según el Análisis Temático, produjeron tres unidades temáticas: Muchos informantes y poca información; Las informaciones ofrecidas por el equipo de salud versus la comprensión de la família; y El "peso/poder" que las hablas de los profesionales de la salud tienen en la vida de las familias. Los resultados mostraron una serie de ruidos en el proceso de comunicación entre el equipo de salud y la familia del niño que sufrió asfixia perinatal grave, perjudicando el proceso dialógico del cuidado

DESCRIPTORES: Ninõs con discapacidad. Familia. Comunicación. Asfixia neonatal. Enfermería. 


\section{INTRODUÇÃO}

A importância da linguagem na existência do ser humano é percebida por ser a forma como ele se comunica com os outros seres humanos, e também pela maneira com que consegue estabelecer suas relações existenciais.

Por intermédio da linguagem, os seres humanos se comunicam e se compreendem. No dia-a-dia e na convivência com os outros é possível falar mesmo quando não se deixa soar nenhuma palavra. ${ }^{1}$ Os seres humanos se comunicam mesmo quando estão em silêncio, porque o decisivo na linguagem não é, em si, a palavra dita, mas o significado a ela atribuído. ${ }^{2}$

Nesse sentido, para que ocorra o diálogo, é preciso buscar as palavras apropriadas, utilizando uma linguagem que tenha significado para ambos os seres humanos envolvidos no diálogo, pois as palavras podem ter ou não a capacidade de alcançar o outro. ${ }^{3}$

Sob essa ótica, passa-se a refletir sobre o uso da linguagem na área da saúde, a fim de pensar nas palavras utilizadas pelos profissionais da saúde, quando constroem uma relação dialógica com as pessoas que desejam cuidar. Esses vocábulos precisam ser pensados antes de serem proferidos para que se tenha de fato um diálogo. As pessoas envolvidas no diálogo precisam compreender umas as outras, para que se tenha efetivamente um processo dialógico. ${ }^{3}$ Caso um dos integrantes do diálogo não compreenda o outro, ele não ocorrerá.

Dessa forma, o estabelecimento de um diálogo entre profissional de saúde e usuário encontra-se fortemente agregado à forma como esse profissional irá conduzir sua linguagem. Conforme os pressupostos gadamerianos, algumas das expressões técnicas da área da saúde são dotadas de uma força enunciativa por si só apenas para os profissionais. Em contrapartida, essa mesma expressão, a qual para o profissional possui um amplo significado, para o usuário pode não ter significação alguma, ou ter um sentido completamente diferente. ${ }^{3}$

Quando duas pessoas estão tentando se comunicar, mas uma não consegue compreender a linguagem utilizada pela outra, não se tem um diálogo, mas sim um monólogo. Sob essa ótica, propõe-se refletir sobre as questões que envolvem o diálogo entre a equipe de saúde e a família da criança que sofreu uma asfixia perinatal grave, pois estudos têm mostrado que, em muitos casos de crianças que nascem com necessidades especiais, os pais não conseguem compreender o quadro clínico da criança, muitas vezes, em virtude da linguagem científica utilizada pela equipe de saúde. ${ }^{4-6}$

Vale ressaltar que o nascimento de uma criança com asfixia perinatal grave causa um desestruturação familiar. ${ }^{4}$ No entanto, as dificuldades enfrentadas pelas famílias podem ser minimizadas quando ocorre a criação de um vínculo de confiança entre ela e a equipe de saúde que está cuidando o Recém-nascido (RN). Porém, a confiança dos pais na equipe de saúde está atrelada a alguns fatores como: esclarecimentos e informações ofertadas à linguagem utilizada, ao tipo de atenção dispensada, à maneira como a equipe acolhe a família e ao convívio entre eles. Quando os pais não estabelecem um vínculo de confiança com a equipe de saúde, fica difícil a ocorrência de uma relação positiva entre eles. ${ }^{7}$

Nessa perspectiva, a comunicação entre a equipe de saúde e a família vem sendo considerada um recurso primordial no processo de adaptação da família à situação de hospitalização do RN, bem como, um facilitador na formação e no fortalecimento do vínculo afetivo entre a díade família/ RN. ${ }^{7}$

Entretanto, na prática diária como enfermeiras, é possível observar certa discrepância entre a linguagem utilizada pelos profissionais da saúde para com as famílias das crianças que nascem com asfixia perinatal grave. Frente a essa situação observada, emerge a necessidade de responder aos seguintes questionamentos: como ocorre a comunicação entre a família da criança que nasce com asfixia perinatal grave e a equipe de saúde? Qual a linguagem que os profissionais da saúde utilizam ao cuidar dessas famílias?

Conforme o exposto objetivou-se conhecer o processo de comunicação entre equipe de saúde e família criança com paralisia cerebral nos três primeiros anos de vida. Trata-se, portanto, de um recorte da investigação da dissertação de mestrado, ${ }^{4}$ cujo objetivo foi conhecer como a família cuida da criança com paralisia cerebral nos três primeiros anos de vida.

\section{TRAJETÓRIA METODOLÓGICA}

Trata-se de uma pesquisa descritiva e exploratória à luz de uma abordagem qualitativa, realizada no período de janeiro a março de 2008, no município de Rio Grande-RS.

Participaram do estudo seis famílias, compostas por seis mães, duas avós maternas e um avô materno, por serem considerados os cuidadores da criança. Os participantes foram identificados 
por: F1Mãe, F1Vó, F2Mãe, F2Vó, F2Vô até a F6Mãe respectivamente, conforme a ordem da entrevista e o grau de parentesco com a criança.

Convém informar que os participantes do estudo foram todas as famílias das crianças que nasceram com Apgar menor ou igual a três no quinto minuto com diagnóstico de asfixia perinatal grave, na cidade do Rio Grande-RS, nos anos de 2005, 2006 e 2007, e que estivessem vivas no momento da coleta das informações. A captação dos participantes ocorreu a partir da consulta em prontuários, das mulheres que passaram pelo processo de parturição, em dois hospitais da cidade.

Os sujeitos foram contatados em suas residências e convidados a participar do estudo. Todos aceitaram fazer parte da pesquisa e assinaram o Termo de Consentimento Livre e Esclarecido. Preservou-se a privacidade dos depoentes respeitando o seu anonimato e o sigilo. As informações foram coletadas por meio de entrevistas semiestruturadas, dentre as quais os pesquisadores efetuaram os seguintes questionamentos: você pode me contar como foi a comunicação entre você e os profissionais da saúde que cuidaram do seu filho(a)? O que falaram para você? As entrevistas foram gravadas e transcritas logo após a sua realização.

Para a interpretação das informações, adotou-se Análise Temática ${ }^{8}$ que consiste em três etapas: pré-análise, exploração dos dados, tratamento dos resultados obtidos e interpretação. Na pré-análise, as informações coletadas foram transcritas na íntegra e realizadas leituras e releituras flutuantes, com a finalidade de tomar contato exaustivo com as informações colhidas. Logo após, procedeu-se à organização das informações transcritas, através da visualização individual de cada entrevista, destacando os aspectos relevantes. Após esta etapa, realizou-se o mapeamento das falas das entrevistas, assinalando os principais pontos de cada fala, para facilitar a visualização do material como um todo. Na etapa de exploração dos dados, foi assinalado, no material, tudo o que era significativo, ou seja, palavras, frases, parágrafos de mesmo conteúdo temático, identificando as unidades de registro e fazendo os recortes necessários. Novas leituras foram realizadas, buscando apreender o significado manifesto e/ou oculto das observações e informações contidas nos relatos, encaminhando a novas reflexões, para agrupar os dados e estabelecer as categorias.

O estudo obteve aprovação do Comitê de Ética em Pesquisa da Associação de Caridade Santa Casa de Rio Grande, sob o número 002/2008.

\section{RESULTADOS E DISCUSSÃO}

Ao dialogar/dar voz as famílias das crianças que sofreram asfixia perinatal grave sobre como ocorreu a comunicação entre elas e a equipe de saúde, foi possível identificar uma série de ruídos no processo de comunicação. A partir da interpretação das informações dos participantes do estudo foram construídas as seguintes unidades temáticas: Muitos informantes e poucas informações; As informações fornecidas pela equipe de saúde versus a compreensão da família; e O "peso/poder" que as falas dos profissionais da saúde têm na vida das famílias.

\section{Muitos informantes e poucas informações}

Essa unidade temática apresenta a percepção da família em relação à quantidade de profissionais da equipe de saúde que davam informações, contrapondo-se a qualidade da informação fornecida. Identificou-se que a ausência de uma pessoa de referência na equipe de saúde foi compreendida como o primeiro ruído na comunicação entre família e equipe. As famílias referiram não encontrar dentre os integrantes da equipe, alguém que lhes fosse como um ponto de referência, como se pode verificar nos trechos que seguem.

Todos os dias, era um médico diferente [...] e diziam coisas diferentes (F3Mãe).

Eu me lembro, assim, que sempre tinha um pediatra diferente, e isso é uma outra coisa que eu acho muito errado, porque cada um te diz uma coisa, cada um tem o seu ponto de vista próprio, um te fala uma coisa, o outro te fala menos (F4Mãe).

A F3Mãe e a F4Mãe remetem à dificuldade que sentiram pela mudança, constante, quase que diária, do profissional que fornece as informações às famílias. Além disso, elas relatam que não existe um consenso entre esses profissionais que prestam essa assistência. Logo, essa situação deixa as famílias confusas e perdidas em relação ao que está acontecendo com a criança, bem como sobre seu prognóstico.

Nas instituições do estudo, as informações sobre o estado de saúde da criança eram proferidas pelo médico de plantão. Entretanto, ao analisar os depoimentos acima, considera-se interessante repensar sobre a participação de outros profissionais no fornecimento de informações à família. Acredita-se que a enfermeira poderia ser responsável pela notícia do estado clínico do recém-nascido, pois ela permanece diariamente com a 
criança, além de ter intrínseco, em sua formação, o preparo para compreender o ser humano em sua multidimensionalidade, facilitando a interação entre ela e a família. Além disso, sua presença diária, junto com a criança e com as famílias, ajudaria os pais a encontrarem, dentro da equipe de saúde, um profissional que atuaria como um ponto de referência, permitindo a família sentir-se mais segura/ confiante em relação à assistência prestada ao seu bebê.

A confiança é considerada a base de qualquer relacionamento, sendo considerado um fator de relevância, decisivo no sucesso e no insucesso de qualquer relação. A sonegação e/ou privação de uma informação pode levar a quebra do vínculo de confiança. ${ }^{9}$ Sendo assim, a família, ao acreditar que os profissionais da saúde não estão apresentando um ou mais fatos em relação ao estado da criança, pode vivenciar uma ruptura na relação de confiança estabelecida com a equipe de saúde.

Existe a necessidade de um intercâmbio de informações entre a equipe e a família, acerca das condições clínicas do recém-nascido. Os pais precisam saber cada passo da internação do filho, pois isso faz com que eles participem mais dos cuidados ao neonato. ${ }^{10}$ Segundo o Estatuto da Criança e do Adolescente (ECA), ${ }^{11}$ os pais ou responsáveis têm direito de participar ativamente do diagnóstico, tratamento e prognóstico da criança, recebendo informações sobre os procedimentos a que será submetida.

Mesmo sendo um direito da criança, de que seus pais sejam sabedores de sua situação, as famílias desse estudo referem que as informações que recebiam eram vagas, como descrevem nas falas:

[...] vinha [profissional da equipe] e falava comigo direitinho [...] ela não dizia muita coisa, sabe, só dizia assim: ah, ela vai ficar oito dias, não sei quantos dias e vai sair. Não diziam muito assim sabe, não entravam em detalhes (F2Mãe).

[...] me diziam quase todos os dias a mesma coisa [...]. Me diziam que aos pouquinhos ela ia melhorar [...]. Todos os dias era a mesma coisa (F3Mãe).

[...] quando melhorava, eles avisavam que estava melhorando. Quando ele aceitava os medicamentos, toda a vez que eles trocavam os medicamentos eles avisavam. Só que eu não sabia o que ele tinha. Eu perguntava e eles diziam: ai mãe, o pulmão dele não tinha se formado entendesse? Tá, e eu ficava pensando, e o que mais? (F5Mãe).

De acordo com os depoimentos, percebe-se que as mães possuíam interesse em obter informações mais objetivas sobre o real estado de saúde de seus filhos. Muitas vezes, a equipe de saúde restringia-se em responder questionamentos sobre rotinas do hospital. Em alguns casos, os familiares nem sabem o que perguntar, porque se encontram numa total ignorância frente à situação. Eles não conseguem compreender o que está acontecendo com a criança, a gravidade do problema e, até mesmo, o motivo pelo qual o recém-nascido necessita estar internado na unidade de tratamento intensivo ou na pediatria. ${ }^{12}$

Outra pesquisa, desenvolvida com mães de crianças que vivem com epidermólise bolhosa, também identificou que se faz necessário o desenvolvimento de uma comunicação mais aberta e consoante entre os profissionais da saúde e as famílias, para que se possibilite uma maior qualidade na relação desses seres humanos. ${ }^{13}$

\section{As informações fornecidas pela equipe de saúde versus a compreensão da família}

Nesta unidade temática, serão apresentadas e discutidas as diferenças de linguagem entre a equipe de saúde e as famílias das crianças que nasceram com asfixia perinatal grave. Os participantes da pesquisa, em alguns casos, possuem dificuldades em compreender a linguagem utilizada pelos profissionais da equipe de saúde.

A incompreensão do que estava acontecendo com a criança, acrescido ao receio de questionar o que não haviam entendido, nas informações fornecidas pela equipe de saúde, levavam as famílias a um desconhecimento do diagnóstico da criança. Como se pode ver na fala que segue:

[...] me disseram que ele tinha nascido com um problema, uma anóxia (F1Mãe).

Essa frase sozinha dá a impressão de que a F1Mãe sabe que seu filho sofreu uma anóxia neonatal severa e que, em decorrência desse episódio, ele necessitou ser internado na Unidade de Terapia Intensiva Neonatal. Entretanto, no momento da entrevista, percebeu-se que a F1Mãe falava com muita naturalidade, meu filho teve uma anóxia, o que instigou a uma das pesquisadoras a perguntar: o que é a anóxia que seu filho teve? Ela respondeu, após uns segundos de silêncio: ah! Eu não sei. Só sei que ele teve uma anóxia, sabe? Uma anóxia no parto (F1Mãe).

Parece tão óbvio a expressão, "ele teve uma anóxia, sabe" que provavelmente a F1Mãe ficou constrangida em questionar o significado do termo, o que demonstra que algumas informações eram resultantes de uma linguagem técnica e 
incompreensível para as pessoas que desconhecem a ciência médica. Quando se fornecem informações aos pais a respeito da criança internada, é imprescindível verificar se os mesmos estão compreendendo a situação. Muitos profissionais possuem posturas incorporadas na relação educador-educando, mediado por relações de poder, em que o educando recebe, passivamente, os conhecimentos advindos do saber profissional, sem questionar, até mesmo, suas dúvidas. ${ }^{12}$

Essa dificuldade de compreensão da família da linguagem utilizada pela equipe de saúde, também foi encontrada em outros estudos, ${ }^{4-5}$ quando as autoras constataram que a comunicação do diagnóstico não trouxe os esclarecimentos necessários para conscientizar os familiares a respeito do estado de saúde da criança, levando-os a permanecerem em um desconhecimento do que de fato era a paralisia cerebral. Situação semelhante ocorreu com a F2Vó, como se pode perceber ao afirmar: falaram que ela podia ter sequelas não caminhar, não falar [...] eu não sei direito o que é que, que disse sequela (F2Vó).

Na fala acima, a F2Vó, de forma semelhante à F1Mãe, também não compreendia o real significado da palavra sequela. A utilização de termos técnicos, desconhecidos na linguagem comum, é considerada um estímulo negativo no processo de adaptação vivenciado pela família. É fundamental compreender que, quando se utiliza uma linguagem simples, trata-se o objeto com seriedade e profundidade suficientemente fácil para que seja apreendida por aqueles, cuja experiência intelectual é diferente do locutor. Este fato permite uma melhor compreensão e esclarecimento de possíveis dúvidas acerca da temática. ${ }^{14}$ Sendo assim, ao esclarecer o diagnóstico, os profissionais da saúde devem utilizar uma linguagem clara, de compreensão simples, e não com terminologias específicas e próprias da área da saúde, pois essas são desconhecidas para a maioria da população. ${ }^{12,14}$

A comunicação entre a família e a equipe deve estar embasada no diálogo, desta forma, coloca-se o emissor e o receptor na condição de sujeitos. ${ }^{14}$ Para tanto, a equipe precisa perceber a família e a criança como partícipes e não como um objeto em que serão realizadas ações durante o processo de trabalho.

Salienta-se que a efetivação desse diálogo entre cuidador e família é um grande desafio, constituindo-se em uma arte e não um poder a ser exercido. Trata-se de um exercício a ser realizado no cotidiano de nossa práxis como profissionais de saúde, e porque não como seres humanos. É um exercício contínuo de buscar a palavra adequada a ser utilizada com o outro, o gesto apropriado, o respeito em relação ao meu ser como indivíduo histórico e em relação ao outro como um ser autêntico, como um ser no-mundo no sentido mais literal e complexo da expressão. ${ }^{1}$

Tendo em vista que a asfixia perinatal grave, caracterizada pelo APGAR menor ou igual a três no quinto minuto, é um indicativo de comprometimento do sistema nervoso central, ${ }^{15-16}$ acarretando uma série de consequências para o crescimento e desenvolvimento da criança, buscou-se conhecer as informações oferecidas pela equipe de saúde às famílias em relação às repercussões da asfixia perinatal grave:

[...] o doutor falou para o meu pai que ela não ia caminhar, que ela ia ter dificuldade [...]. Falou para o meu pai. Mas para mim não falavam muita coisa, falavam mais era para o meu pai e para a minha mãe (F2Mãe).

[...] falei com a médica e ela disse que ela teria problema, para falar, caminhar. Alguma coisa ia acontecer (F2Vô).

[...] teve uma médica que me falou que ela podia fica com uma seqüela, e que ela ainda não podia me dizer com certeza o que seria, [...] ai eu perguntei para outra médica e ela me disse que a princípio não, que ela não teria sequela alguma, [...] que eu não era pra me preocupar com isso (F3Mãe).

Falavam assim, teve isso, teve aquilo. Hoje ela teve isso, sabe, hoje tava assim, ou hoje melhorou alguma coisa [...]. Certas coisas me falavam, mas não me disseram nada assim o, quando tu saí daqui tu leva ela pra fazer uma fisioterapia uma estimulação, isso nunca me falaram (F4Mãe).

As falas dos familiares demonstram que alguns deles receberam a informação de que seus recém-nascidos poderiam desenvolver sequelas, dificuldades para andar, falar, mas devido à impossibilidade para saber a área do cérebro lesionada, bem como sua extensão, não puderam ser informadas, com precisão, as sequelas ocasionadas pela asfixia perinatal. Entretanto, a segunda profissional, que falou com a F3Mãe, disse a ela que sua filha não teria sequela alguma. Essa situação mostra, novamente, a falta de comunicação entre os prórpios integrantes da equipe, visto que cada médica plantonista forneceu a informação para a mãe a partir do seu ponto de vista. A divergência entre ambas, provavelmente, gerou uma confusão na família 3, a qual passou a ter dois prognósticos diferentes em relação à criança. 
A F6Mãe, todavia, refere-se a uma ligação de amizade criada entre ela e a equipe como um elemento facilitador na comunicação: $e$ depois eu fiz amizade, [...] e o pessoal foi comentando que deu complicação, e me explicando sabe? (F6Mãe).

Outro ponto merecedor de destaque refere-se à participação de uma enfermeira ao explicar para a F6Mãe, de uma forma clara, o que havia acontecido e estava acontecendo com seu filho. $A h$, eu tinha tanta dúvida, um dizia que era uma coisa, o outro dizia que era outra coisa [...] até que um dia uma enfermeira foi lá e me disse, te acalma, é assim, assim o problema dele (F6Mãe).

Numa situação de comunicação do diagnóstico, a enfermeira pode auxiliar a família, fornecendo apoio e informações baseados em seus conhecimentos técnicocientíficos e relacionando-os com sua experiência profissional. A enfermeira pode reduzir a ansiedade dos pais, explicando os procedimentos, tratamentos, condições de saúde da criança e os cuidados a serem dispensados. ${ }^{5,12}$

\section{$\mathrm{O}$ "peso/poder" que as falas dos profissionais da saúde têm na vida das famílias}

Essa unidade temática busca refletir a respeito do peso/poder que a linguagem dos profissionais da saúde exerce sobre as famílias às quais prestam assistência.

Torna-se possível perceber, nos trechos a seguir, que, para alguns profissionais de saúde, o recém-nascido é mais um integrante do grupo de risco, de uma amostra estatística.

E aí nos fomos na UTI de noite, eu o pai dela e o meu filho que tem 26 anos. Ai a doutora me disse que o caso dele não era bom. Que era bem grave. Até disse assim para mim, entre $100 \%$ de chance ele tem 5 a 10\%. Era muito pouca chance [...] de sobreviver (F1Vó).

O doutor mesmo falou comigo, disse que era grave [...] que de 10 tirava cinco não lembro bem as palavras dele, mas ele me explicou assim (F6Mãe).

A ciência médica tem comprovado em suas pesquisas, que a criança nascida com um Apgar baixo nos cinco primeiros minutos possui uma probabilidade muito maior de óbito neonatal, quando comparada a uma criança com as mesmas condições, cujo Apgar manteve-se dentro dos valores considerados normais. ${ }^{15}$ No entanto, essa mesma ciência, também, tem comprovado que, com os avanços tecnológicos ocorridos na neonatologia nos últimos trinta anos, tornou-se possível aumentar os índices de sobrevivência de recém-nascidos, cujos prognósticos, há alguns anos, seriam extremante desfavoráveis. ${ }^{17}$

Nessa perspectiva probabilística, a criança, muitas vezes, passa a ser vista como um elemento constituinte de uma amostra, cujas regras estatísticas tentam, cada vez mais, estabelecer e revelar as médias que dirão quais as características dos grupos que irão ou não sobreviver. Sob essa ótica probabilística, questiona-se como serão englobados, nessas variáveis, elementos como os vínculos afetivos da criança, como a capacidade do ser humano de superação. Questiona-se, então, até que ponto tudo pode ser transformado em dados estatísticos e até que ponto o profissional de saúde possui o conhecimento científico para calcular as probabilidades prognósticas.

Afirmar para a família que um RN possui de 5 a $10 \%$ de probabilidade de sobreviver, pode ser considerado um ato "impensado", pois essa probabilidade irá dificultar na formação do vínculo afetivo entre a família e a criança. A família, inconscientemente, poderá adotar um mecanismo de defesa, afastando-se da criança pelo medo de sua morte, praticamente certa ou, até mesmo, poderá intensificar o processo de luto, no qual já se encontra inserida.

Convém ressaltar que os avanços no conhecimento, realizados pela epidemiologia, foram e são importantes para o desenvolvimento da assistência prestada na área da saúde. Não se pode negar a importância da epidemiologia tampouco dos cálculos estatísticos com seus fatores e grupos de risco, mas o que se quer nesse momento, é mostrar que a complexidade que abrange o processo de saúde e de doença do ser humano não se restringe a essas questões.

Os profissionais da saúde, ao almejarem prestar o cuidado ao ser humano, nesse caso, as crianças que nasceram com asfixia periatal grave e suas famílias, precisam incorporar em sua práxis um olhar para além das características morfo-funcionais, passando a compreendê-los como seres inseridos no mundo, olhando menos para a doença e mais para o doente. ${ }^{19} \mathrm{O}$ olhar para o doente significa olhar para o ser humano, e não para a patologia, significa olhar para a criança e para sua família, e não reduzi-los a um número de probabilidade estatística.

As famílias, quando se deparam com o nascimento de uma criança que irá desenvolver necessidades especiais, muitas vezes, buscam e necessitam, consciente ou inconscientemente, compreender o que de fato aconteceu, qual foi o motivo que levou 
o seu filho a desenvolver tais necessidades. Como se pode observar na fala da F4Mãe:

\section{[...] nunca ninguém me disse o porquê [...]} lembro que no início eu queria muito saber o porquê isso aconteceu, eu não tive nada, a minha gestação foi tranqüila, eu não senti dor, eu só senti uma dor nas costas, não senti essa dor horrivel que tem mulheres que chegam gritando na maternidade. Então eu digo: mas porque aconteceu isso ai? Ai, na hora, ele [obstetra] me disse ai, isso aconteceu porque tu não fez força suficiente, que eu tinha que fazer um força comprida e não sei mais o que. No início eu ia nele e agora eu não vou mais [...] ele tava, com outras palavras me culpando por ela ter nascido assim porque eu não tinha feito a força desse jeito que ele disse [...] eu nunca tive filho, como é que eu vou sabe o que é contração, eu não tinha visão porque eu perguntava pra ele sobre o parto, e ele sempre dizia a ainda ta cedo, sabe era sempre assim, ele enrolava e nunca me dizia, muito estranho, e eu nem sabia de nada (F4Mãe).

O trecho acima mostra que quando a F4Mãe foi buscar, com o seu obstetra, uma explicação para o ocorrido. Provavelmente o profissional, por despreparo em lidar com tal situação, e talvez, por estar se sentindo pressionado/incomodado com os questionamentos, encontrou na responsabilização materna a forma mais "fácil" de autoproteção.

Entretanto, de forma consciente ou inconsciente, a mãe já se sente responsabilizada por seu filho ser portador de necessidades especiais..$^{20-21}$ Diante disso, pode-se começar a imaginar como a F4Mãe se sentiu, ao ser responsabilizada pelo que ocorreu com sua filha.

A comunicação, bem como a interação entre a equipe e a família, é essencial para a formação do vínculo entre a criança e a família como para manutenção da saúde mental (psíquica) dessa. Os profissionais de saúde, talvez, desconheçam a "força", o impacto que suas palavras podem ter na vida dos seus clientes. Muitas vezes, as palavras dos profissionais são compreendidas pelos usuários como "regras", "leis", ou seja, normas que devem ser seguidas sem questionamento.

[...] ele [pediatra] disse um dia para mim e para o pai dela que a criança 4 [nome] não era normal. Ele disse a tua filha não é normal, [...] mas como tu vai dizer que uma criança não é normal. Tem braço, tem perna, tem tudo. Não tem como dizer que não é normal. Ele podia dizer, oh, mãe ela tem um problema, ah ela tem um atraso [...] Ai ele me disse que ela não era normal. Ai eu digo ah, não o que não é normal, normal não é ele. E nunca mais eu levei ela nele. Sabe eu fico pensando se eu não conhecesse um pouco da área eu ia fica tratando a minha filha como uma anormal? (F4Mãe).

A F4Mãe consegue expressar a sua indignação pelo pediatra ter dito que sua filha não era "normal", ela ainda argumenta dizendo que, o que não é normal deve ser tratado como "anormal".

A criança que vive com paralisia cerebral possui uma série de necessidades especiais, contudo ela permanece sendo criança, como qualquer outra, que necessita de amor, carinho, educação, disciplina e convívio com outras pessoas. ${ }^{4}$ Sendo assim, o profissional de saúde ao dizer que a criança "não é normal", pode fazer com que a família passe a percebê-la como um ser diferente e, por isso, talvez não precise dos mesmos cuidados que uma criança "normal".

No entanto, para que algo possa ser considerado anormal, é necessário que possua um padrão de "normalidade" para retornar. ${ }^{18}$ Nesse sentido, uma criança com paralisia cerebral, decorrente da asfixia perinatal, não pode ser considerada "anormal", pois ela nasceu com uma série de necessidades especiais, não possuindo outro padrão, que permita a ela, retornar para a "normalidade".

A sociedade considera "normal" o que se encontra na maior parte dos casos de uma espécie determinada ou que constitui a média de uma característica mensurável..$^{18}$ Essa situação leva-nos a refletir sobre o que e quem pode ser considerado normal, por essa normatividade imposta por um paradigma que desconsidera as peculiaridades do ser humano, bem como a veracidade de sua existência. Reitera-se, novamente, a necessidade evidente de se rever os valores com que os profissionais prestam assistência à criança e à família.

\section{CONSIDERAÇÕES FINAIS}

Com a realização desse estudo foi possível conhecer, na perspectiva da família da criança que sofreu asfixia perinatal grave, como ocorreu a comunicação entre ela e a equipe de saúde. Revelando, dessa forma, a problemática vivenciada por essas famílias para compreender o que está acontecendo com o filho recém-nascido.

As informações fornecidas pela equipe para a família foram mediadas, muitas vezes, por uma comunicação em que o receptor e o emissor não se encontravam numa linha horizontal. Expondo essas famílias a uma assistência que desvaloriza sua condição de ser humano. A comunicação apresentou ruídos que prejudicaram o real entendimento da situação de saúde do recém-nascido. 
Os diálogos verticalizados mediaram os processos de comunicação, em que as informações foram referidas pelas famílias como "superficiais". Além disso, foram transmitidas muitas informações sem preocupar-se com sua absorção e entendimento. Constatou-se, em diversos estudos, a importância de a comunicação ocorrer em uma forma horizontal, levando em conta que todos os comunicantes são considerados sujeitos. Acredita-se que o uso do diálogo possa a favorecer a comunicação da equipe de saúde, contribuindo, desse modo, para o estabelecimento de uma interação mais efetiva com a família.

Percebeu-se, também, a relevância da equipe de saúde em fornecer informações de forma clara e precisa, com uma linguagem acessível à família, bem como fazer um feedback para averiguar o nível de compreensão destas informações. Outro aspecto importante é a disponibilidade de escuta da equipe, ou seja, mostrar-se receptiva para esclarecer dúvidas e minimizar as ansiedades das famílias. Considerando que quando as informações são apenas repassadas à família, muitos detalhes se perdem, dificultando sua compreensão e como consequência aumentando seu sofrimento, não conseguindo, assim, produzir o efeito desejável, qual seja, auxiliar a família a enfrentar a doença do filho.

Nessa perspectiva, compreendeu-se que a comunicação dos profissionais de saúde e família da criança que sofreu asfixia perinatal grave ainda se encontra impregnada pela ideologia do paradigma biomédico e tecnicista, em vez de um cuidado centrado na criança e família.

Vale ressaltar a importância dos profissionais de saúde (re)verem seus conceitos, valores e práticas, no que se refere ao cuidado prestado à criança e família, a fim de diminuir a incidência de respostas ineficientes. Reitera-se que o cuidado deve ir além das questões tecnicistas e curativistas. Para tanto, deve-se considerar e incorporar a multidimensionalidade do ser humano e o meio no qual está inserido.

Salienta-se, ainda, que a pesquisa realizada abordou a perspectiva da família, todavia acredita-se na importância da realização de novas pesquisas que busquem conhecer como ocorre essa comunicação na visão da equipe de saúde, além da construção de outras produções científicas sobre temática, com intuito de melhorar o cuidado prestado às crianças que sofrem asfixia perinatal e suas famílias.

\section{REFERÊNCIAS}

1. Heidegger M. A caminho da linguagem. $3^{\mathrm{a}}$ ed. Petrópolis (RJ): Vozes; 2003.

2. Heidegger M. Seminários de Zollinkon. $2^{\mathrm{a}}$ ed. Petrópolis (RJ): Vozes; 2009.

3. Gadamer HG. Hermenêutica em retrospectiva: a posição da filosofia na sociedade. vol. IV. Petrópolis (RJ): Vozes; 2007.

4. Milbrath MM. Cuidado da família à criança portadora de paralisia cerebral nos três primeiros anos de vida. [dissertação]. Rio Grande (RS): Escola de Enfermagem, Fundação Universidade Federal de Rio Grande; 2008.

5. Milbrath VM, Soares DC, Amestoy SC, Cecagno $\mathrm{D}$, Siqueira HCH. Mães vivenciando o diagnóstico da paralisia cerebral em seus filhos. Rev Gaúcha Enferm. 2009 Set; 30(3):437-44.

6. Dantas MAS, Collet N, Moura FM, Torquato IMB. Impacto do diagnóstico de paralisia cerebral para a família. Texto Contexto Enferm. 2010 Abr-Jun; 19(2):229-37.

7. Wernet M. Experiência de tornar-se mãe na unidade de cuidados intensivos neonatais [tese]. São Paulo: Universidade de São Paulo; 2007.

8. Minayo MC. O Desafio do conhecimento: pesquisa qualitativa em saúde. 10a ed. São Paulo: Hucitec, 2007.

9. Valentin IVL, Kruel AJ. A importância da confiança interpessoal para a consolidação do Programa de Saúde da Família. Ciênc Saúde Coletiva. 2007 MaiJun; 12(3):777-88.

10. Guimarães GP, Monticelli M. A formação do apego pais/recém-nascido pré-termo e/ou de baixo peso no método Mãe Canguru: uma contribuição da enfermagem. Texto Contexto Enferm. 2007 Out-Dez; 16(4):626-35.

11. Brasil. Estatuto da Criança e do Adolescente. Lei $\mathrm{N}^{\circ}$ 8.069, de 13 de Julho de 1990. [página na internet]. Brasília; 1990 [citado 2006 Jun 22]. Disponível em: http:/ / www.eca.org.br/eca.htm

12. Sabatés AL, Borba RIH. As informações recebidas pelos pais durante a hospitalização do filho. Rev. Latino-am Enfermagem. 2005; 12(6):968-73.

13. Caprara A, Veras MSC. Hermenêutica e narrativa: a experiência de mães de crianças com epidermólise bolhosa congênita. Interface- Comunic, Saúde, Educ. 2005 Fev; 9(16):131-46.

14. Freire P. Educação e mudança. $30^{\mathrm{a}}$ Ed. Rio de Janeiro: Paz e Terra. 2007.

15. Rotta NT. Paralisia cerebral: novas perspectivas terapêuticas. J Pediatr. 2002; 78(1):48-54.

16. Laffita AB. Factores que influyen en el Apgar al nacer, en el Hospital América Aires de la Habana, Cuba. Rev Chilena Obstet Ginecol. 2005; 70(6):359-63. 
17. Procianoy RS, Guinsburg R. Avanços no manejo do recém-nascido prematuro extremo. J. Pediatr. 2005 Mar; 81, (1 Supl):S1-2.

18. Canguilhem G. O normal e o patológico. Rio de Janeiro: Forense-Universitária. 1978.

19. Ayres JRCM. Uma concepção hermenêutica de saúde. PHYSIS: Rev Saúde Coletiva. 2007 Jan-Abr; 17(1):43-62.
20. Brazelton TB. O Desenvolvimento do apego: uma família em formação. Porto Alegre (RS): Artes Médicas; 1988.

21. Milbrath VM, Cecagno D, Soares, DC, Amestoy SC, Siqueira $\mathrm{HCH}$. Being a womam, mother to a child whith cerebral palsy. Acta Pabul Enferm. 2008 JulAgo; 21(3):427-431. 